\title{
Nelfinavir and Lamivudine Pharmacokinetics during the First Two Weeks of Life
}

\author{
MARK MIROCHNICK, MD ${ }^{1}$, KARIN NIELSEN-SAINES, MD, MPH ${ }^{2}$, JOSE HENRIQUE \\ PILOTTO, MD, PHD ${ }^{3}$, JORGE PINTO, MD, DSC ${ }^{4}$, VALDILEA GONÇALVES VELOSO, MD $^{5}$, \\ STEVE ROSSI, PHD ${ }^{6}$, JACK MOYE, MD ${ }^{7}$, YVONNE BRYSON, MD ${ }^{2}$, LYNNE MOFENSON, \\ MD $^{7}$, MARGARET CAMARCA, RN, MPH ${ }^{8}$, D. HEATHER WATTS, MD ${ }^{7}$, and NICHD HPTN 040/ \\ PACTG 1043 PROTOCOL TEAM \\ ${ }^{1}$ Boston University School of Medicine, Boston, MA, USA \\ 2 David Geffen School of Medicine at UCLA, Los Angeles, CA, USA \\ ${ }^{3}$ Hospital Geral de Nova Iguaçu, Nova Iguaçu and Laboratório de AIDS e Imunologia Molecular/ \\ FIOCRUZ, Rio de Janeiro, Brazil \\ ${ }^{4}$ Universidade Federal de Minas Gerais, Belo Horizonte, Brazil \\ ${ }^{5}$ Fiocruz Institute, Rio de Janeiro, Brazil \\ ${ }^{6}$ University of California, San Diego School of Medicine and Skaggs School of Pharmacy \& \\ Pharmaceutical Sciences \\ ${ }^{7}$ Pediatric, Adolescent, and Maternal AIDS Branch, NICHD, NIH, DHHS, Bethesda, MD, \\ Bethesda, MD, USA \\ 8 Westat, Inc., Rockville, MD
}

\section{Abstract}

Background-There are no previous data describing nelfinavir and lamivudine pharmacokinetics in neonates treated with weight band dosing regimens.

Design-Pharmacokinetic study of nelfinavir and lamivudine pharmacokinetics in infants during the first 2 weeks of life treated with weight band dosing regimens.

Methods-Intensive 12 hour pharmacokinetic profiles were performed between either days 4-7 or days 10-14 of life in 26 Brazilian infants.

Results-Pharmacokinetic data were obtained from 26 infants who received median (range) per $\mathrm{kg}$ doses of $58.8(48.4-79.0) \mathrm{mg} / \mathrm{kg}$ for nelfinavir and $2.0(1.5-3.2) \mathrm{mg} / \mathrm{kg}$ for lamivudine. Median nelfinavir AUC0-12 was $25.5(1.7-183.5) \mu \mathrm{g} * \mathrm{hr} / \mathrm{mL}$ and median $\mathrm{C} 12 \mathrm{~h}$ was $1.09(<0.04$ - 14.44) $\mu \mathrm{g} / \mathrm{mL}$. AUC0-12 was less than $15 \mu \mathrm{g} * \mathrm{hr} / \mathrm{mL}$ (the $10 \%$ percentile for adults) in 12 infants (46\%). Median lamivudine AUC0-12 was $7.8(2.7-15.6) \mu \mathrm{g} * \mathrm{hr} / \mathrm{mL}$ and median $\mathrm{C} 12 \mathrm{~h}$ was 0.23 $(<0.04-0.74) \mu \mathrm{g} / \mathrm{mL}$.

Conclusions-Lamivudine pharmacokinetic parameters observed in this study were consistent with those seen in other studies of neonates. While median nelfinavir AUC and $\mathrm{C} 12 \mathrm{~h}$ in these neonates were above the exposure targets, interindividual variability in nelfinavir exposure was large and nelfinavir exposure failed to meet the exposure targets in $46 \%$ of infants.

Correspondence: Mark Mirochnick, MD, Boston Medical Center, 771 Albany Street - Dowling 4N, Room 4111, Boston, MA 02118, Fax: 617-414-7297, Phone: 617-414-3754, markm@bu.edu. 


\section{Keywords}

Nelfinavir; Lamivudine; Pharmacokinetics; Newborns

\section{INTRODUCTION}

Mother to child HIV transmission can be dramatically reduced with the administration of antiretroviral agents to the mother during pregnancy and labor and to the neonate after birth. However, if the mother does not receive treatment during pregnancy, the optimal composition and duration of postnatal neonatal antiretroviral prophylaxis is unknown. The number of antiretrovirals with formulations suitable for use in neonates and with adequate neonatal safety and pharmacokinetic data is limited, especially among the protease inhibitors. Previous studies of nelfinavir pharmacokinetics in the first weeks of life demonstrated low nelfinavir exposure in a significant number of infants even with nelfinavir doses of $40-45 \mathrm{mg} / \mathrm{kg}$ twice a day. ${ }^{1-2}$

Recent antiretroviral dosing guidelines for low resource settings have recommended treatment with weight band dosing regimens rather than individual dose calculations using weight or body surface area. There have been few previous studies describing antiretroviral exposure with weight band dosing of antiretrovirals in the first weeks of life. The goal of the current study was to describe the pharmacokinetics of nelfinavir and lamivudine during the first 2 weeks of life with use of weight band dosing regimens. The nelfinavir regimen was designed to provide $50-75 \mathrm{mg} / \mathrm{kg}$ per dose.

\section{MATERIALS AND METHODS}

NICHD/HPTN 040/IMPAACT P1043 is a recently completed trial in Brazil, Argentina, South Africa and the US that compared the efficacy of 3 infant regimens ( 6 weeks of zidovudine alone, 2 weeks of nelfinavir/lamivudine plus 6 weeks of zidovudine or 3 doses nevirapine in the first week plus 6 weeks of zidovudine) in preventing mother to child HIV transmission in infants whose mothers receive no ARV therapy during pregnancy. Infants in the nelfinavir arm received zidovudine $(10 \mathrm{mg} / \mathrm{mL}$ syrup), lamivudine $(10 \mathrm{mg} / \mathrm{mL}$ syrup) and nelfinavir ( $50 \mathrm{mg} / \mathrm{gm}$ powder) twice a day according to the following weight based dosing regimen: zidovudine $12 \mathrm{mg}$ if birth weight $>2000 \mathrm{gm}, 8 \mathrm{mg}$ if birth weight $\leq 2000$ gm; lamivudine $6 \mathrm{mg}$ if birth weight $>2000 \mathrm{gm}, 4 \mathrm{mg}$ if birth weight $\leq 2000 \mathrm{gm}$; nelfinavir $200 \mathrm{mg}$ if birth weight $>3000 \mathrm{gm}, 150 \mathrm{mg}$ if birth weight between 2001 and $2999 \mathrm{gm}, 100$ $\mathrm{mg}$ if birth weight $\leq 2000 \mathrm{gm}$. Eligible infants were less than 48 hours old at the time of enrollment and were born to mothers who were identified as HIV positive but received no antiretroviral therapy during the pregnancy. Their mothers may have received oral or intravenous ZDV during labor. Exclusion criteria included gestational age less than 32 weeks, birth weight less than 1500 grams, presence of life-threatening conditions, inability to take oral medication and administration to the mother of any ARV during labor and delivery other than ZDV. Local institutional review boards approved the protocol at all participating sites and signed informed consent was obtained from the mothers of all subjects prior to participation.

Two of the sites participating in the study (Hospital Geral de Nova Iguaçu, Nova Iguaçu, Brazil; Federal Universidade of Minas Gerais, Belo Horizonte, Brazil) elected to participate in a substudy of nelfinavir and lamivudine pharmacokinetics. A separate informed consent was obtained for participation in this substudy. 
Twenty six infants were enrolled in the pharmacokinetic substudy. They were started on nelfinavir and lamivudine within 48 hours of birth and were studied between either days 4-7 or days 10-14 of life. On the study day plasma samples were collected prior to a morning dose and at 1, 2, 4, 8 and 12 hours after the dose.

Nelfinavir and lamivudine plasma concentrations were measured by validated HPLC assays with a lower limit of quantitation (LLOQ) of $0.04 \mu \mathrm{g} / \mathrm{mL}$ for each, as previously described. ${ }^{1}$ Pharmacokinetic calculations were performed using WinNonlin (Pharsight Corporation, Mountain View, CA) and Excel (Microsoft Corporation, Redmond, WA). The nelfinavir exposure targets were 12 hour AUC above $15 \mu \mathrm{g} * \mathrm{hr} / \mathrm{mL}$ (the 10th percentile for adults) and 12 hour concentration above $0.8 \mu \mathrm{g} / \mathrm{mL}$ (the standard trough concentration target used in therapeutic drug monitoring programs). Demographic and pharmacokinetic parameters are presented as medians (range).

\section{RESULTS}

Twenty six infants (9 females, 17 males) were studied, 14 at age $4-7$ days and 12 at age 1014 days. Their median (range) birth weight was 3105 (1775-3900) gm and their median gestational age was 39 (34-42) weeks. They were born to mothers with a median age of 25 (15-42) years, a median HIV viral load of 8622 (224-538773) copies/ml, and a median CD4 cell count of 704 (143-1711) cells/mm3. Fourteen infants received nelfinavir doses of 200 $\mathrm{mg}, 11$ received $150 \mathrm{mg}$ and 1 received $100 \mathrm{mg}$. The median per kg nelfinavir dose was 58.8 (48.4-79.0) $\mathrm{mg} / \mathrm{kg}$. Twenty five infants received lamivudine doses of $6 \mathrm{mg}$ and 1 received 4 $\mathrm{mg}$. The median per kg lamivudine dose was $2.0(1.53 .2) \mathrm{mg} / \mathrm{kg}$.

Nelfinavir concentration-time plots for the infants studied at age 4-7 days and age 10-14 days are presented in Supplemental Digital Content 1 and 2 (figures). The nelfinavir pharmacokinetic parameters are presented in Table 1. No nelfinavir pharmacokinetic parameter differed between infants studied on days 4-7 vs days 10-14. For the combined population at both time points, median nelfinavir AUC0-12 was $25.5(1.7-183.5) \mu \mathrm{g} * \mathrm{hr} /$ $\mathrm{mL}$ and median $\mathrm{C} 12 \mathrm{~h}$ was $1.09(<0.04-14.44) \mu \mathrm{g} / \mathrm{mL}$. AUC0-12 was less than $15 \mu \mathrm{g} * \mathrm{hr} /$ $\mathrm{mL}$ (the $10 \%$ percentile for adults) in 12 infants (46\%). C12h was less than $0.8 \mu \mathrm{g} / \mathrm{mL}$ (the standard nelfinavir therapeutic drug monitoring trough concentration target) in 12 infants (46\%) and was less than $.05 \mu \mathrm{g} / \mathrm{ml}$ (10 times the upper limit for nelfinavir IC50 of wild type HIV) in 2 infants (8\%). Nelfinavir t was not calculated as many of the nelfinavir concentration-time plots demonstrated flat or erratic profiles for which there were insufficient data points to determine a terminal elimination half-life.

Plasma sample volumes from one subject were inadequate to perform the lamivudine assay, so lamivudine pharmacokinetic data are available for 25 subjects. Lamivudine concentration-time plots are presented in Supplemental Digital Content 3 and 4 (figures) and the lamivudine pharmacokinetic parameters are presented in Table 2. Lamivudine $t 1 / 2$ was longer in infants studied on day 4-7 compared to day 10-14 ( $\mathrm{p}=0.04)$. No other lamivudine pharmacokinetic parameter differed between infants studied on days 4-7 vs days 10-14. For the combined population at both time points, median lamivudine AUC0-12 was 7.8 (2.715.6) $\mu \mathrm{g} * \mathrm{hr} / \mathrm{mL}$ and median $\mathrm{C} 12 \mathrm{~h}$ was $0.23(<0.04-0.74) \mu \mathrm{g} / \mathrm{mL}$. Lamivudine $\mathrm{C} 12 \mathrm{~h}$ exceeded the assay LLOQ of $0.04 \mu \mathrm{g} / \mathrm{mL}$ for 22 of 25 subjects (88\%).

\section{DISCUSSION}

Our study is the first to describe nelfinavir and lamivudine pharmacokinetics in infants during the first 2 weeks of life treated with weight band dosing regimens. Weight band dosing was chosen to facilitate study implementation across sites, to simplify drug 
administration to enrolled infants, and to make the results more easily transferable to a variety of settings once the optimum regimen was determined. Weight or age band dosing of antiretrovirals is currently recommended by the WHO for use in low resource settings. ${ }^{3}$ Nelfinavir was chosen as the protease inhibitor used in the study because at the time of initiation of the protocol it was the only protease inhibitor available in a formulation suitable for use in neonates. While liquid formulation lopinavir/ritonavir is now available, there are no lopinavir pharmacokinetic data from infants in the first 2 weeks of life. ${ }^{4}$ In addition, recent reports of life threatening toxicities in premature infants receiving lopinavir/ritonavir have led to a warning against its use in term infants younger than 2 weeks postnatal age and in premature infants younger than 42 weeks postmenstrual age. ${ }^{5}$

Previous studies of nelfinavir pharmacokinetics in neonates have shown significant differences compared with older infants, children and adults. Nelfinavir apparent oral clearance has been shown to be highly variable and to decrease with age, with nelfinavir clearance 2-3 times higher in children aged 2-13 years than in adults and further increased in children below age 2 years. ${ }^{6-9}$ The current recommended dose of nelfinavir in children aged 2-13 years is $45-55 \mathrm{mg} / \mathrm{kg}$ twice a day; there is no approved dose for children under age 2. Previous studies in neonates have shown high variability and inadequate nelfinavir concentrations with doses up to $40-45 \mathrm{mg} / \mathrm{kg}$ twice a day. ${ }^{1-2}$

In the present study we used a weight based nelfinavir dosing regimen that provided a median nelfinavir dose of $58.8 \mathrm{mg} / \mathrm{kg}$ twice a day. The per $\mathrm{kg}$ nelfinavir doses ranged from $18 \%$ below the median dose to $34 \%$ above and are presented graphically in Figure 1. While the median AUC and Cmin in our subjects exceeded the pharmacokinetic targets, interpatient variability was very large, with AUC varying from 1.7 to $183.5 \mu \mathrm{g} * \mathrm{hr} / \mathrm{mL}$. Nearly half $(46 \%)$ of individual subjects failed to meet the AUC or Cmin target. Figure 1 suggests that AUC did not vary with per kg dose administered and that although the per kg doses were greater than those used in previous studies, interpatient variability increased as well, resulting in larger maximum exposures while a significant proportion of subjects remained below the pharmacokinetic target. A recent population analysis of nelfinavir pharmacokinetics in a large group of infants and children suggested that in those less than 2 months nelfinavir doses of $40 \mathrm{mg} / \mathrm{kg}$ twice a day were not adequate and that 50 to $60 \mathrm{mg} / \mathrm{kg}$ three times a day should be studied. ${ }^{10}$ The large amount of interpatient variability in nelfinavir exposure observed in our subjects suggests that a further increase in nelfinavir dosing might result in high and potentially toxic nelfinavir concentrations in some infants along with suboptimal concentrations in others. If nelfinavir is to be used to treat HIV infected neonates during the first weeks of life, however, therapeutic drug monitoring should be encouraged to ensure adequate but not excessive nelfinavir exposure.

Lamivudine elimination was prolonged in these neonates studied during the first week of life compared to older infants and children, consistent with previous studies. ${ }^{11-12}$. Lamivudine is primarily renally eliminated, and its elimination increases during the first weeks and months of life in parallel with postnatal maturation of renal function. ${ }^{12-13}$ Current dosing recommendations for lamivudine are $2 \mathrm{mg} / \mathrm{kg}$ twice a day during the first 4 weeks of life and $4 \mathrm{mg} / \mathrm{kg}$ twice a day after age 4 weeks. The weight band dosing regimen used in the current study resulted in a median dose of $2 \mathrm{mg} / \mathrm{kg}$, with a range of 1.5 to $3.2 \mathrm{mg} / \mathrm{kg}$. While there is no target lamivudine concentration for prevention of HIV infection, lamivudine AUC values were in the same range as those previously observed in prior studies of neonatal and pediatric patients and trough lamivudine concentrations in nearly all subjects exceeded the range of lamivudine IC50 in wild type HIV $(0.0006-.021 \mu \mathrm{g} / \mathrm{ml}) .{ }^{14}$

Mother to child HIV transmission can be reduced to less than $1 \%$ with the use of maternal combination antiretroviral therapy during pregnancy and infant formula feeding. The results 
of the parent protocol of this study demonstrated that when HIV infected pregnant women do not receive combination antiretroviral therapy prior to delivery, treating infants with six weeks of ZDV plus either daily lamivudine/nelfinavir for two weeks or three doses of nevirapine during the first week of life will reduce intrapartum HIV transmission by roughly $50 \% .{ }^{15}$ We have previously reported that nevirapine concentrations with the three dose weight band regimen remain above our prophylactic target of $100 \mathrm{ng} / \mathrm{mL}$ through the first 10 days of life but well below the $3000 \mathrm{ng} / \mathrm{mL}$ trough concentration target used in HIV infected patients receiving nevirapine as part of combination treatment regimens. ${ }^{16}$ As we report here, the weight band nelfinavir regimen resulted in trough nelfinavir concentrations below $0.8 \mu \mathrm{g} / \mathrm{mL}$, the standard nelfinavir trough concentration target for treating HIV infection in nearly half of our subjects, although nearly all had nelfinavir trough concentration above $0.05 \mu \mathrm{g} / \mathrm{ml}$ (10 times the upper limit of nelfinavir IC50 for wild type HIV). While there are no data establishing definitive target concentrations for antiretrovirals used for prevention of HIV infection, the equivalent efficacy of these regimens in reducing intrapartum HIV transmission when used in combination with zidovudine suggests that HIV infection can be prevented with antiretroviral concentrations lower than those used in treatment of HIV infected individuals.

\section{Supplementary Material}

Refer to Web version on PubMed Central for supplementary material.

\section{Acknowledgments}

Sources of Funding: Funded by the Eunice Kennedy Shriver National Institute of Child Health and Human Development (contract NO1-HD33345), and co-sponsored by the HIV Prevention Trials Network (HPTN) and the International Maternal Pediatric Adolescent AIDS Clinical Trials (IMPAACT) Group

We thank the patients and their families who enrolled in this trial. In addition to the authors, members of the NICHD/HPTN 040/PACTG 1043 protocol team include: Belo Horizonte- Federal University of Minas Gerais: Flavia Faleiro Ferreira, Fabiana Kakehasi. Hospital Geral de Nova Iguaçu: Jorge Eurico Ribeiro. Oswaldo Cruz Foundation, Rio de Janeiro (FIOCRUZ): Francisco Inacio Bastos, Beatriz Grinsztejn, Ronaldo Ismerio, Mariza Morgado, Marilia Santini de Oliveira, Valéria Ribeiro. Westat, Inc.: Emmanuel Aluko, Jim Bethel, Yolanda Bertucci, Patty Chen, Barbara Driver, Ruby Duston, Adriana Ferreira, Priya Guyadeen, Sarah Howell, Marsha Johnson, Naomi Leshabane, Lilya Meyerson, Rita Patel, Georgine Price, Susan Raitt, Eunice Yu. NICHD: Jennifer Read, George Siberry. Other protocol team members included Ruth Dickover from the University of CA-Davis, and Elizabeth Smith and Sheryl Zwerski from the National Institute of Allergy and Infectious Diseases, Diane Holland from the University of CA-San Diego Pediatric Pharmacology Laboratory. Pharmaceutical support and representatives included Marita McDonough from Boehringer-Ingelheim Pharmaceuticals, Inc. and Helen Watson from GlaxoSmithKline. This study was supported by NICHD Contract \# HHSN267200800001C (NICHD Control \# N01-HD-8-0001).

\section{References}

1. Mirochnick M, Stek A, Acevedo M, et al. Safety and pharmacokinetics of nelfinavir coadministered with zidovudine and lamivudine in infants during the first 6 weeks of life. J Acquir Immune Defic Syndr. Jun 1; 2005 39(2):189-194. [PubMed: 15905735]

2. Rongkavilit C, van Heeswijk RP, Limpongsanurak S, et al. Dose-escalating study of the safety and pharmacokinetics of nelfinavir in HIV-exposed neonates. J Acquir Immune Defic Syndr. Apr 15; 2002 29(5):455-463. [PubMed: 11981361]

3. WHO Paediatric Antiretroviral Working Group. [Accessed June 12, 2008] Preferred antiretroviral medicines for treating and preventing HIV infection in younger children. 2007. http://www.who.int/hiv/pub/paediatric/ARV_WG_meeting_report_may2008.pdf

4. Chadwick EG, Capparelli EV, Yogev R, et al. Pharmacokinetics, safety and efficacy of lopinavir/ ritonavir in infants less than 6 months of age: 24 week results. AIDS. Jan 11; 2008 22(2):249-255. [PubMed: 18097227] 
5. FDA. Safety alert - Kaletra (lopinavir/ritonavir): Label Change - Serious Health Problems in Premature Babies. March 8. 2011 Accessed at http://www.fda.gov/Safety/MedWatch/SafetyInformation/SafetyAlertsforHumanMedicalProducts/ ucm246167.htm

6. Capparelli EV, Sullivan JL, Mofenson L, et al. Pharmacokinetics of nelfinavir in human immunodeficiency virus-infected infants. Pediatr Infect Dis J. Aug; 2001 20(8):746-751. [PubMed: 11734735]

7. Krogstad P, Wiznia A, Luzuriaga K, et al. Treatment of human immunodeficiency virus 1-infected infants and children with the protease inhibitor nelfinavir mesylate. Clin Infect Dis. May; 1999 28(5):1109-1118. [PubMed: 10452644]

8. Litalien C, Faye A, Compagnucci A, et al. Pharmacokinetics of nelfinavir and its active metabolite, hydroxy-tert-butylamide, in infants perinatally infected with human immunodeficiency virus type 1. Pediatr Infect Dis J. Jan; 2003 22(1):48-55. [PubMed: 12544409]

9. Payen S, Faye A, Compagnucci A, et al. Bayesian parameter estimates of nelfinavir and its active metabolite, hydroxy-tert-butylamide, in infants perinatally infected with human immunodeficiency virus type 1. Antimicrob Agents Chemother. Feb; 2005 49(2):525-535. [PubMed: 15673728]

10. Hirt D, Urien S, Jullien V, et al. Age-related effects on nelfinavir and M8 pharmacokinetics: a population study with 182 children. Antimicrob Agents Chemother. Mar; 2006 50(3):910-916. [PubMed: 16495250]

11. Moodley D, Pillay K, Naidoo K, et al. Pharmacokinetics of zidovudine and lamivudine in neonates following coadministration of oral doses every 12 hours. Journal of clinical pharmacology. Jul; 2001 41(7):732-741. [PubMed: 11452705]

12. Tremoulet AH, Capparelli EV, Patel P, et al. Population pharmacokinetics of Lamivudine in human immunodeficiency virus-exposed and -infected infants. Antimicrob Agents Chemother. Dec; 2007 51(12):4297-4302. [PubMed: 17893155]

13. Heald AE, Hsyu PH, Yuen GJ, Robinson P, Mydlow P, Bartlett JA. Pharmacokinetics of lamivudine in human immunodeficiency virus-infected patients with renal dysfunction. Antimicrob Agents Chemother. Jun; 1996 40(6):1514-1519. [PubMed: 8726029]

14. Coates JA, Cammack N, Jenkinson HJ, et al. (-)-2'-deoxy-3'-thiacytidine is a potent, highly selective inhibitor of human immunodeficiency virus type 1 and type 2 replication in vitro. Antimicrob Agents Chemother. Apr; 1992 36(4):733-739. [PubMed: 1380229]

15. Nielsen-Saines, K.; Watts, H.; Gonçalves Veloso, V., et al. Phase III Randomized Trial of the Safety and Efficacy of 3 Neonatal ARV Regimens for Prevention of Intrapartum HIV-1 Transmission: NICHD HPTN 040/PACTG 1043, Abstract \#124LB. Paper presented at: 18th Conference on Retroviruses and Opportunistic Infections; March 2, 2011; Boston, MA.

16. Mirochnick M, Nielsen-Saines K, Pilotto JH, et al. Nevirapine concentrations in newborns receiving an extended prophylactic regimen. J Acquir Immune Defic Syndr. Mar 1; 2008 47(3): 334-337. [PubMed: 18398973] 


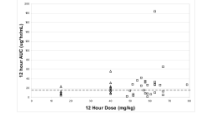

Figure 1.

Scatter plots of nelfinavir AUC versus dose size (normalized to 12 hour dosing) from PACTG $053^{1}$ (open triangles) and current study (open squares). Dashed line represents AUC target of $15 \mu \mathrm{g} * \mathrm{hr} / \mathrm{mL}$. 


\section{Table 1}

Nelfinavir pharmacokinetic parameters for infants studied at ages 4-7 days, 10-14 days and both groups combined. Data presented as medians (ranges). (bql=below quantitation limit of assay of $0.04 \mathrm{ug} / \mathrm{ml}$ ).

\begin{tabular}{|c|c|c|c|}
\hline & 4-7 Days & $\mathbf{1 0 - 1 4 ~ D a y s ~}$ & Combined \\
\cline { 2 - 4 } & $(\mathbf{n = 1 4})$ & $(\mathbf{n = 1 2})$ & $(\mathbf{n = 2 6})$ \\
\hline $\mathbf{t}$ max $(\mathbf{h o u r s})$ & $3(0-8)$ & $4(1-12)$ & $4(0-12)$ \\
\hline $\mathbf{C m a x}(\mathbf{u g} / \mathbf{m L})$ & $2.07(0.42-17.25)$ & $2.86(0.26-4.19)$ & $2.60(0.26-17.25)$ \\
\hline $\mathbf{C 1 2 h}(\mathbf{u g} / \mathbf{m L})$ & $0.81(0.18-14.44)$ & $1.33(\mathrm{bql}-4.06)$ & $1.09(\mathrm{bql}-14.44)$ \\
\hline $\mathbf{A U C 0 - 1 2}(\mathbf{u g} * \mathbf{h r} / \mathbf{m L})$ & $20.7(3.4-183.5)$ & $25.5(1.7-41.7)$ & $25.5(1.7-183.5)$ \\
\hline $\mathbf{C l} / \mathbf{F}(\mathbf{L} / \mathbf{h r} / \mathbf{k g})$ & $3.1(0.3-15.1)$ & $2.7(1.3-35.3)$ & $2.7(0.3-35.3)$ \\
\hline
\end{tabular}


Table 2

Lamivudine pharmacokinetic parameters for infants studied at ages 4-7 days, 10-14 days and both groups combined. Data presented as medians (ranges). (bql=below quantitation limit of assay of $0.04 \mathrm{ug} / \mathrm{ml}$ ).

\begin{tabular}{|c|c|c|c|}
\hline & 4-7 Days & $\mathbf{1 0 - 1 4}$ Days & Combined \\
\cline { 2 - 4 } & $(\mathbf{n = 1 3})$ & $(\mathbf{n}=\mathbf{1 2})$ & $(\mathbf{n}=\mathbf{2 5})$ \\
\hline $\mathbf{t} \mathbf{m a x}(\mathbf{h o u r s})$ & $2.8(1-4)$ & $2.5(1-4)$ & $2.5(1-4)$ \\
\hline $\mathbf{C m a x}(\mathbf{u g} / \mathbf{m L})$ & $1.08(0.38-2.01)$ & $1.27(0.38-2.17)$ & $1.24(0.38-2.17)$ \\
\hline $\mathbf{C 1 2 h}(\mathbf{u g} / \mathbf{m L})$ & $0.31(\mathrm{bql}-0.74)$ & $0.22(\mathrm{bql}-0.62)$ & $0.23(\mathrm{bql}-0.74)$ \\
\hline $\mathbf{A U C 0 - 1 2}\left(\mathbf{u g}{ }^{*} \mathbf{h r} / \mathbf{m L}\right)$ & $7.0(2.9-15.6)$ & $7.9(2.7-14.0)$ & $7.8(2.7-15.6)$ \\
\hline $\mathbf{C l} / \mathbf{F}(\mathbf{L} / \mathbf{h r} / \mathbf{k g})$ & $0.27(0.11-0.70)$ & $0.27(0.14-0.74)$ & $0.27(0.11-0.74)$ \\
\hline $\mathbf{t}^{\mathbf{1} / 2(\mathbf{h o u r s})}$ & $5.3(3.3-10.5)$ & $3.9(3.1-6.3)^{*}$ & $4.7(3.1-10.5)$ \\
\hline
\end{tabular}

p $<0.05$ compared to 4-7 Days 